\title{
ANXIETY AND ITS ASSOCIATED FACTORS AMONG OLDER PATIENTS UNDERGOING CORONARY ANGIOGRAPHY AND PERCUTANEOUS CORONARY INTERVENTION
}

By

EMAN SHOKRY ABD ALLAH ${ }^{1}$, SHERIHAN AWADALLAH ABDELAZIEM ALI ${ }^{2}$, AND HASSANAT RAMADAN ABDEL-AZIZ ${ }^{3}$

Department of Community and Gerontology ${ }^{1}$, and Department of Gerontology ${ }^{2,3}$, Faculty of Nursing, Zagazig University, Egypt

( ${ }^{*}$ Correspondence: emanshokry2012@yahoo.com)

\section{Abstract}

Coronary Angiography and Percutaneous Coronary Interventions (PCI) are diagnostic and therapeutic procedures often for patients with CAD. Although these are minimally invasive and have relatively low risk, most patients showed pre-procedural anxiety. The present study assessed the anxiety level and factors associated with it among older Adults undergoing coronary angiography and percutaneous coronary intervention. A total of 155 older patients undergoing Coronary Angiography and PCI at Cardiac Catheterization Units, Zagazig University Hospitals were selected.

The results showed that $58.1 \%$ of the studied older adults patients had moderate anxiety, while, $25.8 \%$ of them had severe anxiety and only $16.1 \%$ of them had mild anxiety level. The highest rates of anxiety were found in in female patients with age greater than or equivalent to 70 years compared with other age groups, with low educational level, had chest pain attack and those without previously cardiac intervention.

Keywords: Oder Adults, Anxiety level, Associated-factors, Coronary angiography, Percutaneous coronary interventions.

\section{Introduction}

The generation of the older population today is different from that of former generations. People live longer; remain more involved into older age, also more educated and work longer than previous older cohorts (Czaja et al, 2019). But, by 2050 the globe would become 2, 1 billion people aged 65 or over and, for the first time in history the older people worldwide number would exceed the young ones (UN, 2015). Aging is a process of biological, cognitive, and psychosocial transition that starts with conception and extends throughout life (koutoukidis et al, 2013). Blood vessels, especially the coronary arteries, lose their elasticity as the body become older and the arteries walls become thicker and stiffer. Also, ventricles of the heart have be pumped more vigorously to overcome decreased elasticity and increased resistance of older and occluded arteries that increase the coronary artery disease risk (Knight and Nigam, 2017).

Cardiovascular diseases (CVD) are now generally accepted as the leading cause of death and disability. It was estimated that 17.7 million people worldwide died from CVD and by 2030, 23.6 million deaths would occur yearly due to CVD (Shahwan et $a l, 2019)$. Coronary Artery Diseases (CAD) is a common type of cardiovascular diseases, responsible for more than 7.2 million deaths annually (Bennett and Dubois, 2013).

CAD is characterized by narrowing of coronary arteries due to deposition of Atherosclerotic plaques. These plaques may result in partial or complete blockage of coronary arteries, leading to a decreased blood flow and inadequate oxygen supply to the heart (Mangla et al, 2017). CAD's main risk factors for hypertension, obesity, diabetes, hyperlipidemia, and lifestyle risk factors such as cigarette smoking, physical inactivity, and excessive alcoholism (WHO, 2015). Advancing age is the most common cause of coronary artery disease. According to previous researches per 1000 population, new episodes of CAD occur among elderly people, also accounts $28.3 \%$ of total death 2 for those between 65 and 74 years of age, 
$36.3 \%$ for those between $75 \& 84$ years of age and $33 \%$ or those $\geq 85$ years of age (Aljefree and Ahmed, 2015). On the constitute more than $40 \%$ of deaths among people $65-74$ years old and $60 \%$ of people 85 years old and older (Gragasin and Davidge, 2009). Coronary Angiography and PCI are the most common cardiac procedures used for the diagnosis and treatment of CAD. These become usual methods of revascularization among older cardiac patients today (Xaplanteris et al, 2018). Coronary angiography is minimally invasive procedure for an accurate evaluation of coronary artery stenosis which reflected the gold standard for its diagnosis through a special radiopaque contrast agent injected into coronary arteries (Suzuki et al, 2020).

One of the treatments for CAD is PCI by using balloon catheters and specially designed coronary stents to alleviate coronary narrowing and promote effective blood flow to the heart in the occluded coronary artery, through an inflated balloon compresses the atherosclerotic plaque against the vessel wall, therefore allowing clearance and stent application to hold the occluded coronary artery open and to avoid further narrowing (Windecker et al, 2014).

Most patients undergoing coronary angiography or PCI lack awareness of diagnosis and treatment methods of CAD, surgical costs, hospitalization, anesthesia, post-procedural pain and isolation from the family. All these factors may lead to an immediate increase in their anxiety level before underwent coronary interventions (Çetinkaya et $a l$, 2018). Besides, the diagnostic procedures and coronary artery treatment caused the anxiety and fear of death due to a lack of awareness of such operation (Basar et al, 2015). Anxiety is described as a condition in which a person feels worried or fear in response to an unknown and unspecified danger or threats (Delewi et al, 2017). Anxiety can interfere with normal body function; also have a strong negative effect on the physical and psychological health of patient that led to increase some physiolo-gical parameters, such as respiratory rate, heart rate, blood pressure, and catecholami-ne release, thus increasing the myocardial oxygen demand (Ayasrah and Ahmad, 2016).

Gerontological nurses are responsible for establishing a curative and relaxing atmosphere for patients before the invasive procedures, and provide effective psychological interventions to reduce anxiety (Pouyesh et al, 2018). Besides, preoperative anxiety assessment by nurses was a must to minimize patients' emotional distress and fear before coronary interventions; and also to avoid the adverse effects post-surgery by allowing for earlier recovery (Joseph et al, 2015). Also, nurse's duty to provide correct, accurate and reliable information related to coronary interventions could help alleviate stress and anxiety in patients undergoing the surgery (Abollahzadeh et al, 2015).

The study aimed to assess anxiety level and its associated factors among older adult patients undergoing angiography and PCI at Zagazig University Hospitals.

\section{Subjects and Methods}

Study design: Across sectional- descriptive design was utilized, and conducted in the Cardiac Catheterization Units. The subjects eligible for the study included a purposive sample of 155 older patients admitted to the Cardiac Catheterization Units for coronary angiography and percutaneous coronary intervention (PCI), able to communicate and agreed to participate, and who were mental and/or psychological diseases free.

Tools two tools were used to collect data:

Tool I: A structured interview questionnaire was developed by the researcher to collect the necessary data, and consisted of three parts: Part 1: Demographic characteristics of the studied older patients: Entails data about demographic characteristic of the patients as (age, sex, residence, educational status, marital status, current occupation, and monthly income). Part 2: Health profile of the older 3 patients: developed by the authors and involved questions about the medical history 
(chest pain attack, current medication, instructions before undergoing a diagnostic or therapeutic cardiac catheterization). Also, questions about past medical history (type of chronic diseases, hospital admission, previously medical intervention). Also, this part included question about patients' family history. Part 3: Habits of the older patients: This part would be used to assess older patients habits; such as questions about nutritional, smoking and physical activity of the studied older adults patients.

Tool II: Spielberger State Anxiety Inventory (SAI) (Speilberger et al, 1983): The SAI has been used extensively in research and clinical practice to assess the anxiety level induced by stressful experimental procedures and by unavoidable real-life stressors such as imminent surgery and dental treatment. SAI was successfully administered by non-psychiatric trained health researcher as nurses. SAI took five to ten minutes to complete and consisted of twenty items to evaluate how respondents feel at that moment. The 20 items were divided into two groups: ten items were formed to record the anxiety symptoms and the others were scored to record absence of anxiety symptoms. Each item was rated from one (not at all) to four (very much).

Scoring system: Each SAI item was given a weighted score of 1 to 4 . A rating of 4 indicated the presence of a high level of anxiety for ten SAI items (anxiety present items) as ("I feel frightened," "I feel upset"). Besides, a high rating indicates the absence of anxiety for the remaining ten SAI items (anxiety absent items )as( "I feel calm, and I feel relaxed"). The scoring weights for the anxiety-present items were the same as the blackened numbers on the test form while the scoring weights for the anxiety-absent items were reversed, i.e., responses marked $1,2,3$, or 4 were scored $4,3,2$, or 1 , respectively. The anxiety-absent items for which the scoring weights were reversed on SAI were $1,2,5,8,10,11,15,16,19 \& 20$. Total SAI scores ranged from 20 to 80 , with higher scores indicting higher anxiety level, which divided into three levels as fol-lows: SAI scores $>20 \leq 40$, mild anxiety scores $>$ $40 \leq 60$, moderate anxiety and $>60-80$ sever anxiety.

Content validity: The study tools were revised by three experts from Faculty of Nursing (Community Health Nursing Depart ment and Psychiatric Nursing Department) and Faculty of Medicine (Community Medicine Department), Zagazig University. They reviewed the tools content for relevance, clarity, comprehensiveness, and understandability.

Ethical considerations: Study was approved by Research Ethics Committee (REC), Faculty of Nursing at Zagazig University on February 2019. The older patients received a verbal description of the aim of the study, and non-participation or withdrawal rights at any time without giving any explanations. Also, an informed consent for participation was taken verbally from each of the patients after full explanation of the study aim. They were informed that their participation in this study was voluntary, and assured about the confidentiality of the information gathered.

Field work: Once the approval was granted to progress in the study, the authors started to organize a schedule for data collection. They visited the units to be familiar with work process, working time to observe the patients attending the unit to set schedule for data collection. The visits were from eight o'clock before the official working times began where patients went to the catheterization unit early to interview who fulfill the criteria. Until the unit nurses came to talk patients from waiting hall to their room to change their clothes with the hospital ones and each patient was on his bed until the nurse came to prepare him to cardiac catheterization.

Each older patient was interviewed individually $b$ authors who introduced themselves and explained the study aim, and 4 reassured them that information obtained was firmly confidential and would not be used 
for any purposes other than research. The study tool questions were answered by each patient privately. The time needed to fill out the questionnaire ranged from 30 to 40 minutes. Data were collected through four months from the end of April 2019 until the end of August 2019; three days per week (Saturday, Sunday and Wednesday) in Cardiac Catheterization Unit in Sednawy Hospital and one day (Monday ) in second Cardiac Catheterization Unit in Internal Hospital at Zagazig University Hospitals.

Statistical analysis: Data were collected, coded and entered using Personal Computer (PC). Computerized data entry and Statistical analysis were fulfilled using the Statistical Package for Social Sciences (SPSS) version 22. Data were presented using descriptive statistics in form of frequencies, percentages. Chi-square test (X2) was used to compare between qualitative variables. Spearman rank correlation measured strength and direction of association between two ranked variables. Cronbach alpha coefficient was calculated to assess the reliability of the scales through their internal consistency. To identify the independent predictors of the scores of anxiety level, the multiple linear regression analysis was used and analysis of variance for full regression model done. Statistical significant was considered at $\mathrm{P}$ $<0.05$.

\section{Results}

The patients $(46.5 \%)$ were aged ranged between 65to less than 70 years with mean of $65.17 \pm 3.88$ years. As regard to gender and marital status, $62.6 \%$ and $57.4 \%$ of the studied older adults patients were male and married, respectively. In relation to the educational level of the studied older adult patients this table also shows that $31 \%$ of them were illiterate and $28.4 \%$ of them had primary education, respectively. Moreover, only $7.1 \%$ had university education (Tab. 1 ).

The patients $(82.6 \%)$ suffered from chronic diseases and the highly reported diseases were high blood pressure $(71.9 \%)$, diabetes
(35.2\%), and heart disease (28.1\%).

As to history of the patients cardiac diseases $75.5 \%$ were admitted to hospital before for heart problems. Also, as to previous cardiac intervention, $41.9 \%$ of them had a diagnostic cardiac catheterization and $15.5 \%$ of them had a therapeutic cardiac catheterization, and only $13.5 \%$ of them had open heart surgery. As to receiving instruction before, $17.4 \%$ of them received instructions before performing a diagnostic or therapeutic card-iac catheterization. As to the family history $47.7 \%$ of them had positive family history of heart disease (Tab. 2).

Referring to Percentage distribution of the patients according to total Spiel Berger State Anxiety Inventory scores, (Fig. 1) depicts that $58.1 \%$ of them had moderate anxiety level. But, $25.8 \%$ of them had severe anxiety level and only $16.1 \%$ had mild anxiety level. There were highly statistically significant relations between total SAI of patients and their demographic characteristics (marital status, education level, current working and monthly income) at $\mathrm{P}<0.01$. Also, there was significant relation with their ages at $\mathrm{P}$ $<0.05$ (Tab. 3).

There were highly statistically significant relations between total SAI scores of the patients and chest pain attack, receiving instructions, previous diagnostic cardiac catheterization, and therapeutic cardiac catheterization, previous open heart surgery and family history of heart disease at $\mathrm{P}<0.01$. Also, there were statistically significant relations with duration of hospitalization before cardiac catheterization and hospitalization before due to heart problems at $\mathrm{P}<0.05$ (Tab. 4).

The total learning needs, family history of heart diseases, receiving instructions, hospitalization before procedure, having chest pain attack, age, educational level, marital status, hospitalization before due to heart problems and having medical procedure before were significant positive predictors of patient's state anxiety scores (Tab. 5). 
Table 1: Number and percentage distribution of patients according to demographic characteristics $(\mathrm{N}=155)$.

\begin{tabular}{|c|c|c|}
\hline Characteristics & Frequency & Percent \\
\hline \multirow{3}{*}{ 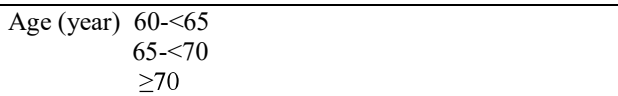 } & 60 & 38.7 \\
\hline & 72 & 46.5 \\
\hline & 23 & 14.8 \\
\hline Mean \pm SD & 65. & \\
\hline Male & 97 & 62.6 \\
\hline Female & 58 & 37.4 \\
\hline Residence Rural & 85 & 54.8 \\
\hline Urban & 70 & 45.2 \\
\hline & 3 & 1.9 \\
\hline $\begin{array}{r}\text { Marital status: } \begin{array}{r}\text { Single } \\
\text { Married }\end{array}\end{array}$ & 89 & 57.5 \\
\hline Divorced & 14 & 9 \\
\hline Widowed & 49 & 31.6 \\
\hline & 48 & 31 \\
\hline $\begin{array}{l}\text { Educational level Illiterate } \\
\text { Read \& write }\end{array}$ & 15 & 9.7 \\
\hline & 44 & 28.4 \\
\hline Secondary education & 37 & 23.9 \\
\hline University / Postgraduate education & 11 & 7.1 \\
\hline \multirow{3}{*}{$\begin{array}{l}\text { Working before retirement Government sector Employee } \\
\text { Private sector } \\
\text { Free business }\end{array}$} & 40 & 25. \\
\hline & 27 & 817 \\
\hline & 13 & 48.4 \\
\hline Farmer & 17 & 11 \\
\hline House wife & 58 & 37.4 \\
\hline Current occupation: Work & 14 & 9 \\
\hline Not work & 141 & 91 \\
\hline \multirow{3}{*}{$\begin{array}{ll}\text { Monthly income } & \text { Sufficient } \\
& \text { Not sufficient } \\
& \text { Sufficient and save }\end{array}$} & 55 & 35.5 \\
\hline & 89 & 57.4 \\
\hline & 11 & 7.1 \\
\hline
\end{tabular}

Table 2: Distribution of elderly patients regarding to their medical history, history of cardiac disease and family

\begin{tabular}{|c|c|c|}
\hline Items & Frequency & Percent \\
\hline \multicolumn{3}{|c|}{ Having chronic diseases $(\mathrm{n}=155)$} \\
\hline Yes & 128 & 82.6 \\
\hline No & 27 & 17.4 \\
\hline \multicolumn{3}{|c|}{ Types of chronic diseases $(n=128) \quad$ (more than one response) } \\
\hline High blood pressure & 92 & 71.9 \\
\hline Diabetes & 45 & 35.2 \\
\hline Heart disease & 36 & 28.1 \\
\hline Arthritis & 4 & 3.1 \\
\hline Chest Diseases & 8 & 6.3 \\
\hline Kidney Diseases & 5 & 3.9 \\
\hline Asthma & 6 & 4.7 \\
\hline Neurological diseases & 3 & 2.3 \\
\hline \multicolumn{3}{|c|}{ Types of current medication } \\
\hline Angina drugs & 152 & 98.1 \\
\hline High cholesterol drugs & 142 & 91.6 \\
\hline Anti-coagulant drugs & 148 & 95.5 \\
\hline Anti-hypertensive drugs & 92 & 59.4 \\
\hline Diabetes mellitus drugs & 45 & 29 \\
\hline Other drugs & 10 & 6.5 \\
\hline \multicolumn{3}{|c|}{ Hospitalization previously for heart problems } \\
\hline Yes & 117 & 75.5 \\
\hline No & 38 & 24.5 \\
\hline \multicolumn{3}{|c|}{ Having Diagnostic Catheter before } \\
\hline Yes & 65 & 41.9 \\
\hline No & 90 & 58.1 \\
\hline \multicolumn{3}{|c|}{ Having Therapeutic Catheter before } \\
\hline Yes & 24 & 15.5 \\
\hline No & 131 & 84.5 \\
\hline \multicolumn{3}{|c|}{ N. of pervious cardiac catheterization $(n=89)$} \\
\hline Once & 55 & 61.8 \\
\hline Twice & 25 & 28.1 \\
\hline Three and above & 9 & 10.1 \\
\hline \multicolumn{3}{|c|}{ Having Open heart surgery before } \\
\hline Yes & 21 & 13.5 \\
\hline No & 134 & 86.5 \\
\hline \multicolumn{3}{|c|}{ Having attack of chest pain } \\
\hline Yes & 134 & 86.5 \\
\hline No & 21 & 13.5 \\
\hline \multicolumn{3}{|c|}{ Family history of heart diseases } \\
\hline Yes & 74 & 47.7 \\
\hline No & 81 & 52.3 \\
\hline
\end{tabular}


Table 3: Relation between demographic characteristics of patients \& total spiel berger state anxiety inventory scores $(\mathrm{N}=155)$.

\begin{tabular}{|c|c|c|c|c|c|c|c|c|c|}
\hline \multirow{3}{*}{\multicolumn{2}{|c|}{ Items }} & \multicolumn{6}{|c|}{ Total Anxiety } & \multirow[t]{3}{*}{$\mathrm{X} 2$} & \multirow[t]{3}{*}{ P-Value } \\
\hline & & \multicolumn{2}{|c|}{ Sever $(n=40)$} & \multicolumn{2}{|c|}{ Moderate $(\mathrm{n}=90)$} & \multicolumn{2}{|c|}{ Mild $(n=25)$} & & \\
\hline & & $\mathrm{N}$ & $\%$ & $\mathrm{~N}$ & $\%$ & $\mathrm{~N}$ & $\%$ & & \\
\hline \multirow{3}{*}{$\begin{array}{c}\text { Age } \\
\text { (year) }\end{array}$} & $60-<65$ & 10 & 25 & 37 & 41.1 & 13 & 52 & \multirow{3}{*}{12.35} & \multirow{3}{*}{$0.01 *$} \\
\hline & $65-<70$ & 12 & 30 & 50 & 55.6 & 10 & 40 & & \\
\hline & $\geq 70$ & 18 & 45 & 3 & 3.3 & 2 & 8 & & \\
\hline \multirow[t]{2}{*}{ Sex } & Male & 21 & 52.5 & 59 & 65.6 & 17 & 68 & \multirow[t]{2}{*}{2.38} & \multirow[t]{2}{*}{0.303} \\
\hline & Female & 19 & 47.5 & 31 & 34.4 & 8 & 32 & & \\
\hline \multirow[t]{2}{*}{ Residence } & Rural & 23 & 57.5 & 45 & 50 & 17 & 68 & \multirow[t]{2}{*}{2.714} & \multirow[t]{2}{*}{0.257} \\
\hline & Urban & 17 & 42.5 & 45 & 50 & 8 & 32 & & \\
\hline \multirow{4}{*}{$\begin{array}{c}\text { Marital } \\
\text { status }\end{array}$} & Single & 0 & 0.0 & 3 & 3.3 & 0 & 0.0 & \multirow[t]{4}{*}{102.59} & \multirow[t]{4}{*}{$.000 * *$} \\
\hline & Married & 24 & 60 & 59 & 65.6 & 6 & 24 & & \\
\hline & Divorced & 0 & 0.0 & 3 & 3.3 & 11 & 44 & & \\
\hline & Widowed & 16 & 40 & 25 & 27.8 & 8 & 32 & & \\
\hline \multirow{5}{*}{$\begin{array}{c}\text { Educa- } \\
\text { tional } \\
\text { level }\end{array}$} & Illiterate & 18 & 45 & 30 & 33.3 & 0 & 0.0 & \multirow[b]{5}{*}{88.35} & \multirow[b]{5}{*}{$.000^{* *}$} \\
\hline & Read \& write & 3 & 7.5 & 12 & 13.3 & 0 & 0.0 & & \\
\hline & Primary education & 6 & 15 & 24 & 26.7 & 14 & 56 & & \\
\hline & Secondary education & 13 & 32.5 & 24 & 26.7 & 0 & 0.0 & & \\
\hline & Post Graduate Studies & 0 & 0.0 & 0 & 0.0 & 11 & 44 & & \\
\hline \multirow{2}{*}{$\begin{array}{c}\text { Current } \\
\text { work }\end{array}$} & Work & 0 & 0.0 & 3 & 3.3 & 11 & 44 & \multirow[t]{2}{*}{44.73} & \multirow[t]{2}{*}{$.000^{* *}$} \\
\hline & Not work & 40 & 100 & 87 & 96.7 & 14 & 56 & & \\
\hline \multirow{3}{*}{$\begin{array}{l}\text { Monthly } \\
\text { income }\end{array}$} & Sufficient & 22 & 55 & 61 & 67.8 & 6 & 24 & \multirow{3}{*}{65.16} & \multirow{3}{*}{$.000 * *$} \\
\hline & Not sufficient & 18 & 45 & 29 & 32.2 & 8 & 32 & & \\
\hline & Sufficient \& save & 0 & 0.0 & 0 & 0.0 & 11 & 44 & & \\
\hline
\end{tabular}

*significant at $\mathrm{p}<0.05, * *$ highly significant at $\mathrm{p}<0.01$.

Table 4: Relation between health history of patients and total Spiel Berger State Anxiety Inventory scores ( $\mathrm{n}=155)$.

\begin{tabular}{|c|c|c|c|c|c|c|c|c|c|}
\hline \multicolumn{2}{|l|}{ Items } & \multicolumn{2}{|c|}{ Sever $(n=40)$} & \multicolumn{2}{|c|}{ Moderate $(n=90)$} & \multicolumn{2}{|c|}{ Mild $(n=25)$} & \multirow[t]{2}{*}{$\mathrm{X} 2$} & \multirow[t]{2}{*}{ P- Value } \\
\hline & & $\mathrm{N}$ & $\%$ & $\mathrm{~N}$ & $\%$ & $\mathrm{~N}$ & $\%$ & & \\
\hline \multirow{3}{*}{$\begin{array}{l}\text { Duration of hospitalization } \\
\text { before current cardiac catheter- } \\
\text { ization (in days) }\end{array}$} & $<3$ & 30 & 75 & 75 & 83.3 & 15 & 60 & \multirow[b]{3}{*}{10.21} & \multirow[b]{3}{*}{$0.013 *$} \\
\hline & $3-5$ & 5 & 12.5 & 10 & 11.1 & 5 & 20 & & \\
\hline & $>5$ & 5 & 12.5 & 5 & 5.6 & 5 & 20 & & \\
\hline \multirow[t]{2}{*}{ Having attack of chest pain } & Yes & 39 & 97.5 & 89 & 98.9 & 6 & 24 & \multirow[t]{2}{*}{99.30} & \multirow[t]{2}{*}{$.000 * *$} \\
\hline & No & 1 & 2.5 & 1 & 1.1 & 19 & 76 & & \\
\hline \multirow[t]{2}{*}{ Receiving instructions } & Yes & 2 & 5 & 5 & 5.6 & 20 & 80 & \multirow[t]{2}{*}{31.90} & \multirow[t]{2}{*}{$.000^{* *}$} \\
\hline & No & 38 & 95 & 85 & 94.4 & 5 & 20 & & \\
\hline \multirow[t]{2}{*}{ Having chronic diseases } & Yes & 35 & 87.5 & 74 & 82.2 & 19 & 76 & \multirow[t]{2}{*}{1.434} & \multirow[t]{2}{*}{.488} \\
\hline & No & 5 & 12.5 & 16 & 17.8 & 6 & 24 & & \\
\hline \multirow{2}{*}{$\begin{array}{l}\text { Hospitalization previously for } \\
\text { heart problems }\end{array}$} & Yes & 26 & 65 & 74 & 82.2 & 17 & 68 & \multirow[b]{2}{*}{5.341} & \multirow[b]{2}{*}{$0.045^{*}$} \\
\hline & No & 14 & 35 & 16 & 17.8 & 8 & 32 & & \\
\hline \multirow{2}{*}{$\begin{array}{l}\text { Previous Diagnostic cardiac } \\
\text { Catheterization }\end{array}$} & Yes & 12 & 30 & 36 & 40 & 17 & 68 & \multirow[t]{2}{*}{9.454} & \multirow[t]{2}{*}{$.006^{* *}$} \\
\hline & No & 28 & 70 & 54 & 60 & 8 & 32 & & \\
\hline \multirow{2}{*}{$\begin{array}{l}\text { previous Therapeutic cardiac } \\
\text { catheterization }\end{array}$} & Yes & 2 & 5 & 2 & 2.2 & 20 & 80 & \multirow[t]{2}{*}{33.43} & \multirow[t]{2}{*}{$.002 * *$} \\
\hline & No & 38 & 95 & 88 & 97.8 & 5 & 20 & & \\
\hline \multirow[t]{2}{*}{ previous Open heart surgery } & Yes & 1 & 2.5 & 1 & 1.1 & 19 & 76 & \multirow[t]{2}{*}{90.33} & \multirow[t]{2}{*}{$.000 * *$} \\
\hline & No & 39 & 97.5 & 89 & 98.9 & 6 & 24 & & \\
\hline \multirow[t]{2}{*}{ Family history of heart disease } & Yes & 6 & 15 & 57 & 63.3 & 11 & 44 & \multirow[t]{2}{*}{26.09} & \multirow[t]{2}{*}{$.000 * *$} \\
\hline & No & 34 & 85 & 33 & 36.7 & 14 & 56 & & \\
\hline
\end{tabular}

*significant at $\mathrm{p}<0.05$. **highly significant at $\mathrm{p}<0.01$.

Table 5: Best fitting multiple linear regression models for SpielBerger State Anxiety Inventory scores.

\begin{tabular}{|c|c|c|c|c|c|c|c|}
\hline \multirow{2}{*}{\multicolumn{3}{|c|}{ Items }} & & $\begin{array}{c}\text { Unstandardized } \\
\text { Coefficients }\end{array}$ & \multirow{2}{*}{$\begin{array}{c}\begin{array}{c}\text { standardized } \\
\text { Coefficients }\end{array} \\
\text { Beta }\end{array}$} & \multirow[b]{2}{*}{$\mathrm{T}$} & \multirow[b]{2}{*}{ P. value } \\
\hline & & & $\mathrm{B}$ & $\begin{array}{c}\text { Standard } \\
\text { error }\end{array}$ & & & \\
\hline \multicolumn{3}{|l|}{ Age } & .561 & .247 & .054 & 13.482 & $.014^{*}$ \\
\hline \multicolumn{3}{|c|}{ Educational level } & .811 & .114 & .11 & 11.023 & $.021^{*}$ \\
\hline \multicolumn{3}{|c|}{ Marital status } & .624 & .712 & .217 & 2.407 & .117 \\
\hline \multicolumn{3}{|c|}{ Monthly income } & .608 & .015 & .054 & 16.334 & $.001 * *$ \\
\hline \multicolumn{3}{|c|}{ Hospitalization before cardiac catheterization } & .654 & .321 & .556 & 22.641 & $.000 * *$ \\
\hline \multicolumn{3}{|c|}{ Having chest pain attack } & .221 & .005 & .461 & 6.251 & $.024 *$ \\
\hline \multicolumn{3}{|c|}{ Receiving instructions before procedures } & .846 & .357 & .610 & 19.550 & $.001 * *$ \\
\hline \multicolumn{3}{|c|}{ Hospitalizing before because of heart problems } & .259 & .441 & .087 & 18.006 & $.002 * *$ \\
\hline \multicolumn{3}{|c|}{ Having medical procedure before (cardiac catheterization- open heart surgery) } & .623 & .331 & .197 & 19.558 & $.001 * *$ \\
\hline \multicolumn{3}{|c|}{ Family history of heart diseases } & .628 & .402 & .114 & 20.171 & $.000 * *$ \\
\hline \multicolumn{3}{|c|}{ Learning needs } & .498 & .269 & .177 & 21.399 & $.000^{* *}$ \\
\hline \multicolumn{8}{|c|}{ Model summary } \\
\hline Model & $\mathrm{R}$ & R square & \multicolumn{2}{|c|}{ Adjusted R square } & \multicolumn{3}{|l|}{ Std. error of estimate } \\
\hline Regression & .954 & .910 & \multicolumn{2}{|c|}{.864} & \multicolumn{3}{|l|}{.524} \\
\hline
\end{tabular}

a. Dependent Variable: Anxiety level, b. Predictors: (constant) Age, educational level, marital status, income....etc. 


\section{Discussion}

Coronary angiography and PCI are the most effective approaches for diagnosing coronary artery disease and treating it. Although advantages of immediate procedure and fast recovery after operation, there are lack of awareness and inadequate information about the coronary procedures, so patients have high stress, worries and anxiety during pre-operation (Yang et al, 2019).

With reference to anxiety level of studied older adults patients undergoing coronary angiography and PCI, mostly of them had pre-procedural anxiety. The findings of the present study also revealed that one quarter of them had severe anxiety, whereas more than half of them had moderate anxiety and less than one fifth had low anxiety level.

Possible explanations for such outcomes are; firstly, this may be due to that those patients are psychologically prepared themselves for poor outcomes after these procedures. Often, they are afraid of survival and may suffer from pain or discomfort during the operation. Secondly, the setting is unfamiliar for them as patients come to cardiac catheterization on the same morning day of the operation. This agreed with Sharif et al. (2014) in Iran who found a substantial correlation between length of hospitalization and patient total anxiety level, as short hospital stay before coronary angiography and PCI associated with high level of anxiety. Finally, most patients were not given the requisite procedural instructions so deficit information on coronary angiography and PCI was another cause for pre-procedural anxiety.

Also, this result agreed with Jamshidi et al. (2012) who revealed that over $82 \%$ of patients coronary angiography had experienced stress and anxiety, and Moradi and Adib (2015) in Iran who revealed that most patients undergoing coronary angiography had moderate to severe anxiety before operation. Ayasrah and Ahmad (2016) in Jordan who reported that high score of anxiety on patients one day before percutaneous coronary interventions Moreover, Rejeh et al. (2016) in Tehran reported that anxiety, particularly before invasive procedures such as coronary angiography, is a common phenomenon in hospitalized patients. Delewi et al. (2017) in Amsterdam measured anxiety levels of patients undergoing coronary procedures in the catheterization laboratory and found that PCI patients had a high grade of anxiety before operation, which decreased substantially after the operation. Besides, Shen et al. (2018) in China found that coronary angiography and PCI as being an invasive technique may increase the risk of preoperative stress and anxiety, and patients may not be familiar with this procedure.

Tel et al. (2011) in Turkey found that patients felt anxiety before coronary angiogramphy at either small or medium rates. Gallagher et al. (2010) in Australia reported that the patient had low to moderate rates of anxiety before coronary angiogramphy and percutaneous coronary intervention. Also, Chang et al. (2020) in China reported that the anxiety was found in only $6.3 \%$ of pre-PCI patients, but there was a substantial increase in anxiety level after operation.

The present results showed that several factors affected anxiety level of older patients under the study as age, sex, educational level, chest pain attack, family history of heart diseases, previous hospitalization, history of coronary intervention, receiving instructions previously and learning needs of older patients.

As regards to age, there was a significant relation between the ages and total anxiety level, supported by the multiple linear regression models, which showed that the patients' age was significant positive predictor of older patient's anxiety scores. This finding might be due to the fact that older individuals were more worry about their health, families, and losing independency or they expected to die if exposed to the interventions. This agreed with Delewi et al. (2017) who revealed that patients under the age of 65 had higher score of anxiety than others.

In the present study, there was a significant 
relation between the educational status and total anxiety level; as highly educated patients had low levels of anxiety before coronary angiography and PCI. This finding was supported by the multiple linear regression models, which showed that the patients' educational level was a significant positive predictor of older patient's anxiety scores.

No doubt, the educated people have sufficient information about the procedure by inquiring it from the doctor or by searching on the internet and other media. This result agreed with Williams et al. (2013); Re et al. (2016); Gu et al. (2016) and Delewi et al. (2017) who reported that highly educated patients were with low rates of anxiety.

The current study showed a significant relation between patients who had chest pain attack and total anxiety level that increased their chest pain attack. This agreed with Ozdemir et al. (2015) in Turkey who reported higher rates of anxiety in patients with angina symptoms while waiting several weeks to months before operation. Atik et al. (2015) found higher total anxiety scores in patients who experienced chest pain attacks, and Basara et al. (2015) in Turkey by who examined rates of anxiety in patients with chest pain admitted to the emergency department and reported that anxiety is a common symptom among patients with chest pain and whose undergoing percutaneous coronary intervention anticipated higher levels of anxiety from chest pain. Besides, de Heer et al. (2020) in Netherlands, who examined whether chest pain increased the risk of anxiety and found that chest pains predicted more extreme anxiety level.

The present results found a positive relation between patients with previous history of hospitalization, cardiac intervention and total anxiety level, where these patients had heart problem without previously cardiac intervention experienced a high anxiety level. No doubt, heart diseased patients were nervous particularly they would be subjected to unaccepted situation. Another explanation might due to the fact that they neither have previous history of coronary intervention nor sufficient knowledge regarding coronary intervention, unfamiliar with catheterization unit, anesthesia.

The present results agreed with Yilmaz et al. (2012) who reported substantial differences in total anxiety level between those who had prior experience of cardiac intervention and those who had not previously undergone cardiac catheterization. Hernández-Palazón (2018) who found that patients with no previous anesthetic experience and previously hospitalized with elevated rates of anxiety prior to coronary interventions. Besides Phusanga et al. (2019) explored the prevalence of anxiety in coronary angiogram and coronary percutaneous intervention, and found that prior history of hospitalization in patients undergoing coronary angiogram \& PCI due to heart disease as risk factors for rising their anxiety level. Besides, the current study results showed significant relation between family history of heart diseases and patients total anxiety level, confirmed by multiple linear regression models. The patients without family history of heart disease had a high level of anxiety while those with family history had a low level of anxiety.

The present result may be due to that patients with a family history of cardiovascular diseases had sufficient knowledge and had prior experiences with their families regarding invasive procedures used in the diagnosis and treatment of coronary diseases and became familiar with the interventions with low anxiety level before coronary angiography and PCI. But, Ramesh et al. (2017) in India found no correlation between the anxiety level and history family of heart disease.

The present study reported significant relation between receiving instructions before regarding their condition and patient's total anxiety level. The findings were further confirmed by multiple linear regression models which demonstrated that receiving instructions previously was statistically significant positive predictor of older patient's state anxiety scores. This may be due to the good 
preparation patients appropriately and providing some knowledge about health and the invasive procedure they would subject to reduce their anxiety level and fear. Ozdemir et al. (2015) reported that one of the most significant causes of anxiety was lack of knowledge about CAD's diagnosis and treatment. But, Varaei et al. (2013) in Iran found the efficacy of information on coronary angiography in reducing patient anxiety.

\section{Conclusion}

Most patients undergoing coronary angiography and PCI experienced anxiety just before the operation. The findings of the present study also revealed that one quarter of them had severe anxiety, whereas more than half had moderate anxiety and less than one fifth had low anxiety level. The highest rates of anxiety are found in in female patients, patients whose age was greater than or equivalent to 70 years compared with other age groups, those with low educational level, had chest pain attack, those had not previously cardiac intervention and who weren't receive any instructions regarding these coronary interventions.

\section{Recommendations}

Evaluating anxiety level of patients undergoing coronary angiography and PCI before operation, develop psychological nursing strategies for psychological preparation to patients before Coronary angiography and PCI very important relieving the patient's anxiety and fear, particularly during the preoperative period. Implementing non-pharmacological alternative therapies; as muscle relaxation, aromatherapy, meditation, music therapy, massage therapy and reflexology to minimize pre procedural anxiety level.

\section{Acknowledgments}

The authors would like to thank the patients who underwent cardiac catheterization and shared the necessary information.

\section{References}

Abollahzadeh, F, Moghaddasian, S, Rahmani, A, Shahmar, M, 2015: Effect of video education in native language on the anxiety level of patients undergoing coronary angiography. Qom Univ. Med. Sci. J. 8, 6:53-60.
Aljefree, N, Ahmed, F, 2015: Prevalence of cardiovascular disease and associated risk factors among adult population in the Gulf region: a systematic review. Advances in Public Health, Hindawi Publishing; 1-23. http://dx.doi.org/ 10. 1155/2015/235101

Atik, D, Atik, C, Karatepe, H, Karatepe, C, Cinar, S, 2015: The effect on anxiety level of coronary angiographic result and the perception of pain. Int. J. Res. Med. Sci. 3, 2:391-400.

Ayasrah, SM, Ahmad, MM, 2016: Educational video intervention effects on periprocedural anxiety levels among cardiac catheterization patients: A randomized clinical trial. Res. Theory Nurs. Pract. 30, 1:70-84.

Basar, C, Beşli, F, Keçebaş, M, Kayapınar, O, Turke, Y, 2015: The effect of audio-visual education prior to coronary angiography on the state anxiety. Clin. Case Repts Rev. 1, 8:176-8.

Bennett, J, Dubois, C, 2013: A novel platinum chromium everolimus-eluting stent for the treatment of coronary artery disease. Biol. Targ. Therap. 7, 1:149-59.

Çetinkaya, F. Așiret, GD, Yilmaz, CK, İnci, S, 2018: Effect of listening to music on anxiety and physiological parameters during coronary angiography: A randomized clinical trial. Euro J. Integr. Med. 23:37-42.

Chang, Z, Guo, AQ, Zhou, AX, Sun, TW, Ma, LL, et al, 2020: Nurse-led psychological intervention reduces anxiety symptoms and improves quality of life following percutaneous coronary intervention for stable coronary artery disease. Austral. J. Rur. Hlth. 1-8. https://doi.org/ 10. 1111 / ajr.12587.

Czaja, SJ, Boot, WR, Charness, N, Rogers, WA, 2019: Designing for Older Adults: Principles and Creative Human Factors Approaches. CRC Press; 1-3.

de Heer, EW, Palacios, JE, Adèr, HJ, van Marwijk, HW, Tylee, A, et al, 2020: Chest pain, depression and anxiety in coronary heart disease: Consequence or cause? A prospective clinical study in primary care. J. Psychosom. Res. 129:1-6.

Delewi, R, Vlastra, W, Rohling, WJ, Wagenaar, TC, Zwemstra, M, et al, 2017: Anxiety levels of patients undergoing coronary procedures in the catheterization laboratory. Inter. J. Cardiol. 228:926-30.

Gallagher, R, Trotter, R, Donoghue, J, 2010: Preprocedural concerns and anxiety 
assessment in patients undergoing coronary angiography and percutaneous coronary interventions. EuroJ. Cardiovasc. Nurs. 9, 1: 38-44.

Gragasin, FS, Davidge, ST, 2009: The effects of propofol on vascular function in mesenteric arteries of the aging rat. Am. J. Physiol. Heart Circ Physiol. 297, 1:H466-74.

Gu, G, Zhou, Y, Zhang, Y, Cui, W, 2016: Increased prevalence of anxiety and depres sion symptoms in patients with coronary artery disease before and after percutaneous coronary intervention treatment. BMC Psychiat. 16, 295:1-9.

Hernández-Palazón, J, Fuente-García, D, Falcón-Araña, L, Roca-Calvo, MJ, Burguillos-López, S, et al, 2018: Assessment of preoperative anxiety in cardiac surgery patients lacking a history of anxiety: contributing factors and postoperative morbidity. J. Cardiothor, Vasc. Anesth. 32, 1:236-44.

Jamshidi, N, Abaszade, A, Najafi-Kaliani, M, 2012: Stress, anxiety and depression of patients before coronary angiography. Zahedan J. Res. Med. Sci. 13, 10:29-37.

Knight, J, Nigam, Y, 2017: Anatomy and physiology of ageing. 1: Cardiovascular syst em. Nurs. Times 113, 2:22-4.

Koutoukidis, G, Stainton, K, Hughson, J, 2013: Tabbner's Nursing Care: Theory and Practice. $\left(6^{\text {th }}\right.$ ed). China: Elsilvier.

Mangla, A, Oliveros, E, Williams Sr, KA, Kalra, DK, 2017: Cardiac imaging in the diagnosis of coronary artery disease. Curr. Probl. Cardiol. 42, 10:316-66.

Moradi, M, Hajbaghery, A, 2015: State and trait anxiety in patients undergoing coronary angiography. Int. J. Hosp. Res. 4, 3: 123-8

Ozdemir, PG, Selvi, Y, Boysan, M, Ozdemir, M, Akdağ, S, et al, 2015: Relationships between coronary angiography, mood, anxiety and insomnia. Psychiat. Res. 228, 3:355-62.

Phusanga, P, Suntibenchakul, S, Sanguanwong, S, 2019: Prevalence of anxiety and depression in prospective underwent coronary angiogram or percutaneous coronary intervention at Sirindhorn Cardiac Center
Phramongkutklao Hospital: A 3 month prospective study. Chulalongkorn Med. Bull. 1, 2:155-66.

Pouyesh, V, Amaniyan, S, Haji Hoseini, M, Bashiri, Y, Sieloff, C, et al, 2018: The effects of environmental factors in waiting rooms on anxiety among patients undergoing coronary angiography: a randomized controlled trial. Inter. J. Nurs. Pract. 24, 6:1-7. Ramesh, C, Nayak, BS, Pai, VB, George, A, George, LS, et al, 2017: Pre-operative anxiety in patients undergoing coronary artery bypass graft surgery-A cross-sectional study. Inter. J. Afri. Nurs. Sci. 7: 31-36.

Re, GL, De Luca, R, Muscarneri, F, Dorangricchia, $P$, Picone, $D$, et al, 2016: Relationship between anxiety level and radiological investigation: Comparison among different diagnostic imaging exams in a prospective single-center study. La Radiol. Med. 121, 10:763-8.

Rejeh, N, Heravi-Karimooi, M, Tadrisi, SD, Jahani, A, et al, 2016: The impact of listening to pleasant natural sounds on anxiety and physiologic parameters in patients undergoing coronary angiography: a pragmatic quasi-randomized-controlled trial. Compl. Therap. Clin. Pract. 25:42-51.

Shahwan, AJ, Abed, Y, Desormais, I. Magne, J, Preux, PM, et al, 2019: Epidemiology of coronary artery disease and stroke and associated risk factors in Gaza Community, Palestine. PloS One 14, 1:1-11.

Sharif, F, Moshkelgosha, F, Molazem, Z, Kalyani, MN, Vossughi, M, 2014: The effects of dis-charge plan on stress, anxiety and depression in patients undergoing percutaneous transluminal coronary angioplasty: a randomized controlled trial. Inter. J. Comm. Based Nurs. Midwi. 2, 2:60-8.

Shen, X, Zhu, X, Wu, Y, Zhou, Y, Yang, L, et al, 2018: Effects of a psychological intervention pro-gram on mental stress, coping style and immune function in percutaneous coronary intervention patie-nts. PloS One 13, 1:1-13.

Speilberger, CD, Gorusch, RK, Lushene, RE, 1983: State-trait anxiety inventory for adults: sampler set, manual, test, scoring key;[form Y]; STAIS-AD, Mind Garden.

Suzuki, N, Asano, T, Nakazawa, G, Aoki, J, 
Tanabe, K, et al, 2020: Clinical expert consensus document on quantitative coronary angiography from the Japanese Association of Cardiovascular Intervention and Therapeutics. Cardiovascul. Interv. Therap. 35:105-16.

Tel, H, Sayın, YY, Yılmaz, M, Güneş, P, 2011: P01-401-Anxiety in patients before coronary angiography. Euro Psychiat. 26, 1: 404-10.

UN 2019: Department of Economic and Social Affairs: World population prospects: available at http://esa.un.org/unpd/ wpp/.

Varaei, SH, Cheraghi, MA, Seyedfatemi, N, Talebi, M, Bahrani, N, et al, 2013: Effect of peer education on anxiety in patients candidated for coronary artery bypass graft surgery: a randomized control trial. J. Nurs. Educ. 2:28-37.

Williams, JB, Alexander, KP, Morin, J, Langlois, Y, Noiseux, N, et al, 2013: Preoperative anxiety as a predictor of mortality and major morbidity in patients aged more than70 years undergoing cardiac surgery. Am. J. Cardiol. 111, 1:137-42.

Windecker, S, Kolh, P, Alfonso, F, 2014:
ESC/EACTS-guidelines on myocardial revascularization. the task force on myocardial evascularization of the European Society of Cardiology (ESC) and the European Association for Cardio-Thoracic Surgery (EACTS). Eur. Heart J. 31, 20:2501-55.

WHO, 2015: Cardiovascular diseases (CVDs) [Fact sheet 317]. Retrieved from http://www. who. int/ mediacentre/factsheets/fs317/en

Xaplanteris, P, Fournier, S, Pijls, NH, Fearon, WF, Barbato, E, et al, 2018: Five-year outcomes with PCI guided by fractional flow reserve. New Engl. J. Med. 379, 3:250-9.

Yang, Y, Huang, L, Luo, X, Chen, Q, 2019: Application of diversified nursing in percutaneous transluminal coronary intervention and its effect on negative emotions. Inter. J. Clin. Exp. Med. 12, 11:12998-3004.

Yilmaz, MY, Sayin, Y, Tel, H, 2012: The information needs and anxiety levels of the patients undergoing coronary angiography, before the procedure. Turk. Klinik. Hemsire. Bilimleri. $4,2: 55-65$

\section{Explanation of figure}

Fig. 1: Percentage distribution of older adults patients according to total Spiel Berger State Anxiety Inventory scores (N=155).

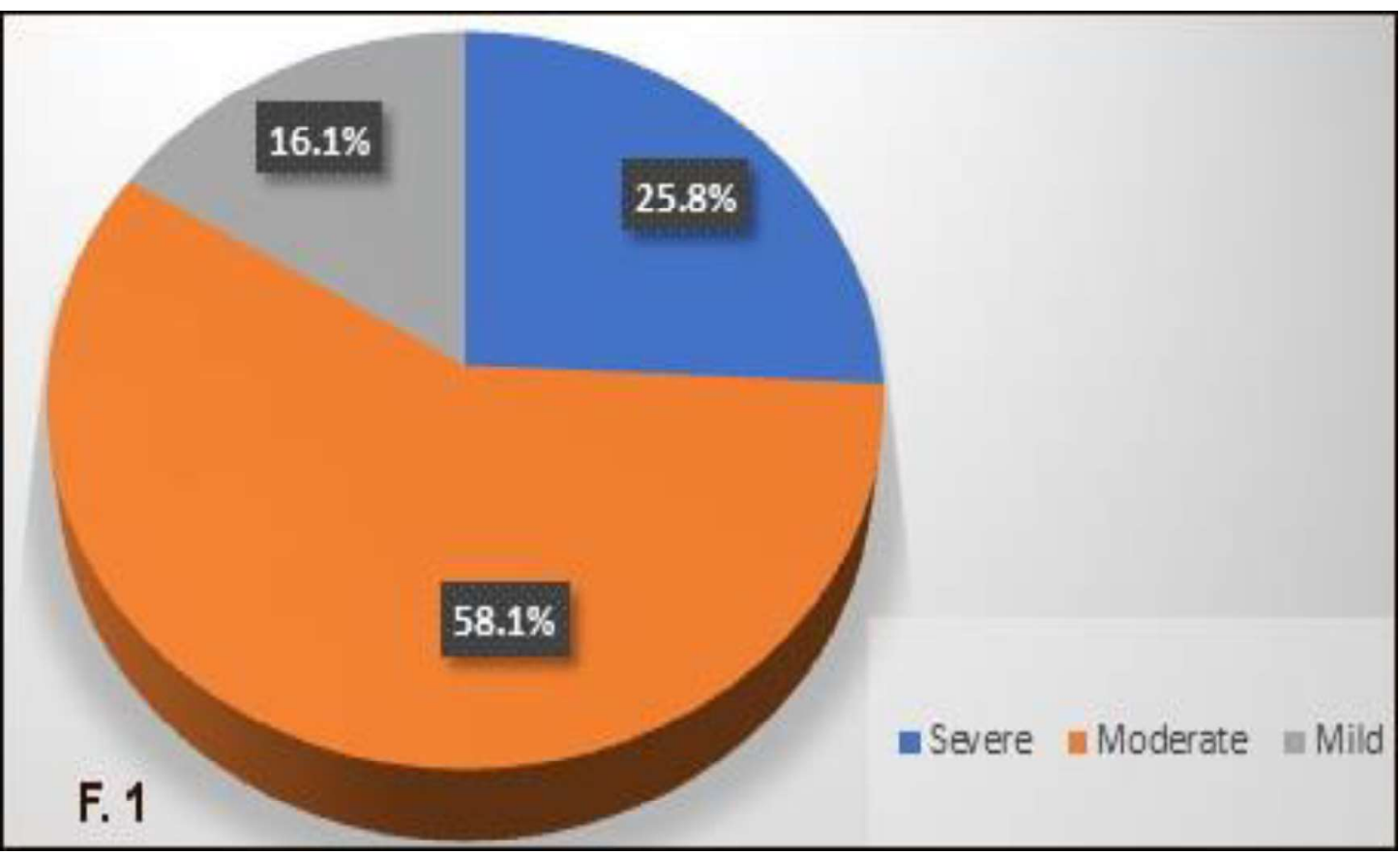

